\title{
Neural correlates of eating disorders: translational potential
}

\author{
This article was published in the following Dove Press journal: \\ Neuroscience and Neuroeconomics \\ I September 2015 \\ Number of times this article has been viewed
}

\author{
Carrie J McAdams ${ }^{1,2}$ \\ Whitney Smith' \\ 'University of Texas at Southwestern \\ Medical Center, ${ }^{2}$ Department of \\ Psychiatry, Texas Health Presbyterian \\ Hospital of Dallas, Dallas, TX, USA
}

Correspondence: Carrie J McAdams University of Texas at Southwestern Medical Center, 5323 Harry Hines BL 6.I I0, Dallas, TX 75390-8828, USA

$\mathrm{Tel}+\mathrm{I} 2146484 \mid 45$

Fax + I 214648532I

Email carrie.mcadams@utsouthwestern. edu

\begin{abstract}
Eating disorders are complex and serious psychiatric illnesses whose etiology includes psychological, biological, and social factors. Treatment of eating disorders is challenging as there are few evidence-based treatments and limited understanding of the mechanisms that result in sustained recovery. In the last 20 years, we have begun to identify neural pathways that are altered in eating disorders. Consideration of how these pathways may contribute to an eating disorder can provide an understanding of expected responses to treatments. Eating disorder behaviors include restrictive eating, compulsive overeating, and purging behaviors after eating. Eating disorders are associated with changes in many neural systems. In this targeted review, we focus on three cognitive processes associated with neurocircuitry differences in subjects with eating disorders such as reward, decision-making, and social behavior. We briefly examine how each of these systems function in healthy people, using Neurosynth meta-analysis to identify key regions commonly implicated in these circuits. We review the evidence for disruptions of these regions and systems in eating disorders. Finally, we describe psychiatric and psychological treatments that are likely to function by impacting these regions.
\end{abstract}

Keywords: anorexia nervosa, bulimia nervosa, social cognition, reward processing, decisionmaking

\section{Introduction}

Eating disorders are complex multifactorial diseases without a clear pathogenesis. Eating disorders are diagnosed based on specific constellations of disordered cognitions and behaviors. Those behaviors include restrictive eating patterns, compulsive overeating behaviors, and purging behaviors. Anorexia nervosa (AN) is defined as an illness with pronounced restrictive eating patterns that result in weight loss in concert with a distorted perception of one's size and shape and self-worth. Binge-eating disorder (BED) is characterized by compulsive overeating behaviors. Bulimia nervosa (BN) is characterized by both compulsive overeating in concert with purging behaviors and a tight link between one's self-worth and one's appearance. Eating disorders have high levels of morbidity and mortality rates ${ }^{1-3}$ and evidence-based treatments for eating disorders are few. ${ }^{4-7}$

The objective of this targeted review is to consider eating disorder treatments in the context of the current understanding of healthy brain function based primarily on cognitive neuroscience studies. First, we briefly consider expected nutritional problems that may result from eating disorder behaviors and lead to alterations in brain function. Next, we evaluate the evidence for alterations in reward pathway function, decision-making abilities, and social behavior in eating disorders. Neurosynth meta-analyses are used 
to provide an overview of the neural regions that have been connected with each of these cognitive processes. Functional magnetic resonance imaging papers examining these three cognitive processes were identified using a systematic, targeted review of the literature. Finally, we interpret alterations in the function of these pathways in the context of both studies of healthy subjects and treatment interventions utilized in eating disorders. Overall, the objective of this review is to provide an understanding of the types of cognitive neuroscience evidences that support various eating disorder treatment methodologies as well as to suggest future directions in translating neuroimaging data toward treatment.

\section{Methods}

This targeted review focuses on considering the insights into translational treatments of people with eating disorders that can be gleaned from cognitive neuroimaging studies. First, an overview of the acute problems expected from nutritional factors related to eating disorders is provided. These are fundamental factors that impact the efficacy of all treatments. Next, a systematic review identifies evidence that the roles of three major neural systems in healthy people are disrupted in EDs: reward processes, decision-making processes, and social brain function. Each of the terms ("reward," "decision," and "social") was selected because 1) the neural circuitry associated with these processes has been a focus of multiple imaging studies in healthy subjects, 2) the healthy studies include a wide range of specific task paradigms, and 3 ) considerable literature, both imaging and clinical work, has focused on these topics in eating disorder patients. Further restriction of these search terms, such as dividing social into self or theory-of-mind, both reduces the saliency of the network visualized in the meta-analyses, and greatly limits the number of relevant studies conducted in eating disorder populations.

Finally, a Neurosynth reverse-inference meta-analysis was conducted to provide a general reference that visualizes the neural networks commonly engaged by each of these processes using the terms "reward," "decision," and "social." these maps at a $P_{\text {FDR }}<0.01$ are provided. Neurosynth extracts 1) verbal descriptive terms from the abstracts of published neuroimaging studies in concert with 2) coordinates of the neural regions reported in the tables of the manuscripts. The reverse-interference meta-analysis provides an automated method to analyze these studies, providing an overview of neural systems relevant to the search terms. For the systematic and targeted review of these topics in eating disorders, PubMed (1809 to February 2015) was searched in the following manner: the patient descriptor "Eating Disorders," "Anorexia Nervosa," "Bulimia Nervosa," or "Binge-Eating Disorder" was combined with the term "Neuroimaging." Then, it was combined with one of the following terms "Reward," "Social," "Decision," or "Decision-Making." The resulting articles were screened to include only those studies comparing eating disorder subjects with healthy comparison human subjects (HC) and utilizing functional magnetic resonance imaging. Papers that were review articles, case studies, involved multiple eating disorder populations without health controls, and healthy control only studies were outside the scope of the systematic review. Six additional articles referenced by the identified articles and relevant to the review topics were also included. The resulting searches identified a total of 32 papers, which are summarized in Tables 1-3.

\section{Results}

This review article is focused on the identification of cognitive neuroimaging data with translational relevance for the treatment of eating disorders. Three themes were identified by the authors in the course of the review that were particularly important and appropriate for a systematic review utilizing cognitive neuroimaging studies such as reward, decision, and social processing. However, it would be inappropriate to ignore the potential role that nutritional factors have on both brain development and on function. As such, the results section begins with a review of nutritional factors that relate to eating disorder symptoms. Following that section, results are organized by each search term, with each major section beginning with a description of the Neurosynth meta-analysis results. This Neurosynth meta-analysis allows a quantitative view of neural regions typically engaged during reward, decision, and social function tasks in healthy people. Each of these is followed by a section examining the neuroimaging studies in eating disorders identified in the systematic review. Based on the search of the eating disorder literature, papers utilizing similar paradigms, examining the same eating disorder diagnoses, or activating similar regions were described together.

\section{Acute challenges to a healthy brain in eating disorders}

There are a number of challenges in studying brain function in patients with eating disorders. The first is obvious, and a healthy brain function depends on a steady source of nutrients from all food groups. All eating disorders can interfere 
Table I Functional MRI studies of reward in eating disorders

\begin{tabular}{|c|c|c|c|}
\hline Author & Participants & Stimuli & Neural differences \\
\hline \multicolumn{4}{|c|}{ Food-based studies of reward pathways in ED } \\
\hline Wagner et $\mathrm{al}^{48}$ & $\begin{array}{l}\text { recAN } 16 \\
\mathrm{HC} 16\end{array}$ & $\begin{array}{l}\text { Pseudorandom boluses of either } \\
\text { sucrose or water. }\end{array}$ & Insula hypoactivation in $\mathrm{AN}$ after sucrose infusion. \\
\hline Schienle et $\mathrm{al}^{58}$ & $\begin{array}{l}\text { BED } 17 \\
\text { BN } 14 \\
\text { HC-N } 19 \\
\text { HC-O } 17\end{array}$ & $\begin{array}{l}\text { Shown food items, disgust items, and } \\
\text { neutral objects. Only compare food- } \\
\text { disgust images. }\end{array}$ & $\begin{array}{l}\text { Food pictures associate with increased activation of OFC, } \\
\text { ACC, and insula in all groups. BED patients have highest } \\
\text { OFC responses to food. BN had greater ACC activation, } \\
\text { and insula activation to food. No difference in groups with } \\
\text { disgust images or neutral images. }\end{array}$ \\
\hline Brooks et $a^{54, *}$ & $\begin{array}{l}\text { AN } 18 \\
\text { BN } 8 \\
\text { HC } 24\end{array}$ & Shown images of food vs objects. & $\begin{array}{l}\text { BN - HC: less bilateral STG/insula activity for food than HC. } \\
B N-A N \text { : more caudate, insula, superior temporal. }\end{array}$ \\
\hline Brooks et $\mathrm{al}^{51, *}$ & $\begin{array}{l}\text { AN } 18 \\
\text { HC } 24\end{array}$ & Shown images of food vs objects. & AN - HC: more visual and prefrontal activations to food. \\
\hline Cowdrey et a $\left.\right|^{49}$ & $\begin{array}{l}\text { recAN I5 } \\
\mathrm{HC} 16\end{array}$ & $\begin{array}{l}\text { Viewing, tasting, rating both positive } \\
\text { and negative flavors and images. }\end{array}$ & $\begin{array}{l}\text { AN - HC: elevated activations in ventral striatum (positive } \\
\text { taste), occipital (positive image), insula/putamen (negative } \\
\text { taste), and ACC and caudate (negative image). }\end{array}$ \\
\hline Frank et al $\mathrm{a}^{56, *}$ & $\begin{array}{l}\text { BN } 20 \\
\text { HC } 23\end{array}$ & $\begin{array}{l}\text { Boluses of sucrose, no solution, and } \\
\text { artificial saliva administered with } \\
\text { visual stimuli, examined responses to } \\
\text { expected vs unexpected pairing. }\end{array}$ & $\begin{array}{l}\text { BN showed reduced brain response compared to } \mathrm{HC} \text { for } \\
\text { unexpected receipt and omission of taste stimuli in insula, } \\
\text { ventral putamen, amygdala, and OFC. }\end{array}$ \\
\hline Bohon and Stice ${ }^{57, *}$ & $\begin{array}{l}\mathrm{BN} 13 \\
\mathrm{HC} 13\end{array}$ & $\begin{array}{l}\text { View and sometimes receive taste } \\
\text { of milkshake or water. Mood rating } \\
\text { before scan. }\end{array}$ & $\begin{array}{l}\text { BN: increased activation of putamen, caudate, pallidum when } \\
\text { anticipating milkshake when sad. }\end{array}$ \\
\hline Oberndorfer et al $\mathrm{l}^{50, *}$ & $\begin{array}{l}\operatorname{rec} A N ~ I 4 \\
\operatorname{recBN~} 14 \\
\mathrm{HC} \mathrm{I4}\end{array}$ & $\begin{array}{l}\text { Pseudorandom boluses of sucrose and } \\
\text { sucralose. }\end{array}$ & $\begin{array}{l}A N-H C \text { : reduced } R \text { ant insula to sucrose. } \\
B N-H C \text { : increased } R \text { ant insula to sucrose. }\end{array}$ \\
\hline Weygandt et al $\left.\right|^{59}$ & $\begin{array}{l}\text { BED } 17 \\
\text { BN } 14 \\
\text { HC-N } 19 \\
\text { HC-O } 17\end{array}$ & $\begin{array}{l}\text { Shown food items, disgust items, and } \\
\text { neutral objects. Compare food to } \\
\text { neutral objects. }\end{array}$ & $\begin{array}{l}\text { Pattern recognition techniques identify insula as selective } \\
\text { for food and differences in ventral striatum, insula, and OFC } \\
\text { with diagnostic relevance. }\end{array}$ \\
\hline Holsen et $\mathrm{al}^{52}$ & $\begin{array}{l}\text { AN } 12 \\
\text { recAN } 10 \\
\text { HC II }\end{array}$ & $\begin{array}{l}\text { Viewing high and low-caloric food } \\
\text { images as well as objects shown } \\
\text { before and after standardized meal. }\end{array}$ & $\begin{array}{l}\text { AN and recAN: less hypothalamus, insula, and amygdala } \\
\text { activity for high calorie food images before meal. } \\
\text { AN: less insula response to food post-meal; less } \\
\text { hippocampus and OFC pre-meal than controls. }\end{array}$ \\
\hline \multicolumn{4}{|c|}{ Monetary-based studies of reward pathways in ED } \\
\hline Wagner et al ${ }^{60, *}$ & $\begin{array}{l}\text { recAN I3 } \\
\mathrm{HC} \mathrm{I3}\end{array}$ & $\begin{array}{l}\text { Guessing game paradigm with rewards } \\
\text { based on accuracy of guesses. }\end{array}$ & $\begin{array}{l}\text { recAN with more caudate activation during task than } \mathrm{HC} \text {. } \\
\text { recAN do not differentiate winning and losing in the dorsal } \\
\text { caudate and anterior ventral striatum like the } \mathrm{HC} \text {. }\end{array}$ \\
\hline Wagner et al ${ }^{61, *}$ & $\begin{array}{l}\text { recBN } 10 \\
\mathrm{HC} 10\end{array}$ & $\begin{array}{l}\text { Guessing game paradigm with rewards } \\
\text { based on accuracy of guesses. }\end{array}$ & $\begin{array}{l}\text { recBN do not differentiate winning and losing in the dorsal } \\
\text { caudate and anterior ventral striatum like the } \mathrm{HC} \text {. }\end{array}$ \\
\hline $\begin{array}{l}\text { Bischoff-Grethe } \\
\text { et al }{ }^{62, *}\end{array}$ & $\begin{array}{l}\text { rec teenAN } 10 \\
\text { teenHC I2 }\end{array}$ & $\begin{array}{l}\text { Guessing game paradigm with rewards } \\
\text { based on accuracy of guesses. }\end{array}$ & $\begin{array}{l}\text { teen } \mathrm{AN} \text { with more posterior executive and striatal } \\
\text { activations in responses to losses than } \mathrm{HC} \text {. } \\
\text { Both teen groups with more limbic and striatal responses to } \\
\text { wins vs losses. }\end{array}$ \\
\hline Balodis et al ${ }^{63}$ & $\begin{array}{l}\text { BED } 19 \\
\text { HC-N } 19 \\
\text { HC-O } 19\end{array}$ & $\begin{array}{l}\text { Monetary incentive delay task with } \\
\text { an anticipation period and a receipt } \\
\text { period for wins and losses. }\end{array}$ & $\begin{array}{l}\text { HC-O relative to } \mathrm{HC}-\mathrm{N} \text { with increased ventral striatal and } \\
\text { vmPFC activity during anticipation. } \\
\mathrm{HC}-\mathrm{O} \text { relative to BED with increased ventral striatal activity } \\
\text { during anticipation. } \\
\text { No differences BED and } \mathrm{HC} \text { in ventral striatum. }\end{array}$ \\
\hline Wierenga et al ${ }^{140}$ & $\begin{array}{l}\text { recAN } 23 \\
\mathrm{HC} 17\end{array}$ & $\begin{array}{l}\text { Delayed discounting task both when } \\
\text { hungry and satiated. }\end{array}$ & $\begin{array}{l}\text { HC show increased ventral striatum, caudate, and anterior } \\
\text { cingulate activation for immediate monetary reward when } \\
\text { hungry and increased insula and vIPFC when satiated. } \\
\text { recAN showed no differences related to hunger status. }\end{array}$ \\
\hline
\end{tabular}

Note: *Similar tasks presented adjacent to these studies.

Abbreviations: ACC, anterior cingulate cortex; AN, anorexia nervosa; BED, binge-eating disorder; BN, bulimia nervosa; ED, eating disorder; HC, healthy controls; HC-N, healthy controls normal weight; $\mathrm{HC}-\mathrm{O}$, healthy controls obese; MRI, magnetic resonance imaging; OFC, orbitofrontal cortex; recAN, recovered anorexia nervosa; recBN, recovered bulimia nervosa; STG, superior temporal gyrus; vIPFC, ventrolateral prefrontal cortex; vmPFC, ventromedial prefrontal cortex; rec teenAN, recovered teenagers with anorexia nervosa; teen $\mathrm{HC}$, teenagers healthy control; $\mathrm{R}$ ant, right anterior. 
Table 2 Functional MRI studies of decision-making in eating disorders

\begin{tabular}{|c|c|c|c|}
\hline Author & Participants & Stimuli & Neural differences \\
\hline Marsh et $\mathrm{al}^{87, *}$ & $\begin{array}{l}\text { BN } 20 \\
\text { HC } 20\end{array}$ & $\begin{array}{l}\text { Simon spatial incompatibility task to } \\
\text { assess self-regulation/impulsivity. }\end{array}$ & $\begin{array}{l}\text { BN: less activation of ILPFC, inferior frontal gyri, ACC, putamen, } \\
\text { caudate. More dACC activation during errors in BN. }\end{array}$ \\
\hline Marsh et $a^{88, *}$ & $\begin{array}{l}\text { teenBN } 18 \\
\text { teenHC } 18\end{array}$ & $\begin{array}{l}\text { Simon spatial incompatibility task to } \\
\text { assess self-regulation and conflict } \\
\text { resolution. }\end{array}$ & $\begin{array}{l}\text { BN: less activity in frontostriatal circuit during correct trials, } \\
\text { including left inferior frontal gyrus, posterior cingulate, and } \\
\text { superior frontal gyrus. }\end{array}$ \\
\hline Marsh et al ${ }^{90, *}$ & $\begin{array}{l}\mathrm{BN} 34 \\
\mathrm{HC} 34\end{array}$ & $\begin{array}{l}\text { Structural analysis of brain surfaces in } \\
\text { subjects from above two studies using } \\
\text { Simon Spatial Incompatibility. }\end{array}$ & $\begin{array}{l}\text { Reduced gray matter in frontal and temporal regions in } \mathrm{BN} \text {. } \\
\text { Further, reduction of inferior frontal gyri correlated with } \\
\text { symptom severity measures in } \mathrm{BN} \text {. }\end{array}$ \\
\hline Lock et al ${ }^{91}$ & $\begin{array}{l}\text { AN-BP/BN } 13 \\
\text { AN-R } 14 \\
\text { HC I3 }\end{array}$ & $\begin{array}{l}\text { Go/No-Go paradigm comparing } \\
\text { correct-No-Go with correct Go. }\end{array}$ & $\begin{array}{l}\text { AN-BP/BN group has more activity in bilateral precentral gyrus, } \\
\text { ACC, and middle and superior temporal gyri than HC; also more } \\
\text { hypothalamus and DLPFC than AN-R and HC. }\end{array}$ \\
\hline Decker et $\mathrm{al}^{80}$ & $\begin{array}{l}\text { AN-R } 13 \\
\text { AN-BP } 10 \\
\text { HC } 23\end{array}$ & $\begin{array}{l}\text { Delayed discounting task before and } \\
\text { after weight restoration of patients. }\end{array}$ & $\begin{array}{l}\text { When underweight, AN with less striatum and } \mathrm{dACC} \text {. When } \\
\text { weight-restored, AN with increase striatum, dACC, PFC, parietal } \\
\text { HC opposite effect with repetition of task. }\end{array}$ \\
\hline Kullmann et al ${ }^{92}$ & $\begin{array}{l}\text { AN } 12 \\
\text { HC-Athlete } 12 \\
\text { HC } 14\end{array}$ & $\begin{array}{l}\text { Go/No-Go paradigm to examine } \\
\text { response inhibition using food/nonfood } \\
\text { images and people active/rest. }\end{array}$ & $\begin{array}{l}\text { Food/nonfood: hypoactive right putamen in AN. } \\
\text { Active/rest: AN group with increased PFC response inhibition; } \\
\text { somatosensory cortex correlates with exercise commitment. }\end{array}$ \\
\hline
\end{tabular}

Note: *Similar tasks presented adjacent to these studies.

Abbreviations: ACC, anterior cingulate cortex; AN, anorexia nervosa; AN-BP, binge-purge anorexia nervosa; AN-R, restricting anorexia nervosa; BED, binge-eating disorder; BN, bulimia nervosa; dACC, dorsal anterior cingulate cortex; DLPFC, dorsolateral prefrontal cortex; HC, healthy controls; ILPFC, inferiolateral prefrontal cortex; $\mathrm{MRI}$, magnetic resonance imaging; PFC, prefrontal cortex; recBN, recovered bulimia nervosa; recAN, recovered anorexia nervosa; teenHC, teenagers healthy control; teenBN, teenagers with bulimia nervosa; $\mathrm{R}$ ant, right anterior.

with healthy brain function by disrupting nutrient supplies. This problem is most obvious in AN when nutrient intake is insufficient to maintain body weight, but it can also be a factor in $\mathrm{BN}$ and $\mathrm{BED}$, due to the selective restriction of particular food groups and binge-eating behaviors. Neurons utilize glucose as their sole energy source. Glucose is most readily obtained from simple sugars and carbohydrates, foods commonly restricted during dieting behaviors. ${ }^{9}$ Additionally, the structure of the brain is entirely composed of myelin, a high-density fat that surrounds neurons throughout the brain. Fat is another substance that is commonly excluded from the diet during restricting behaviors. ${ }^{10}$ Both carbohydrate and fat consumption is reduced in patients with AN. ${ }^{11,12}$ Fat consumption is more consistently reduced in overall diet in $\mathrm{BED}$ and $\mathrm{BN}$, although the most common foods consumed during binges are carbohydrates. ${ }^{12,13}$ Importantly, most substantial neurodevelopmental changes are related to myelination of neurons, permitting faster neurotransmission between specific regions of the brain. ${ }^{14,15}$ During adolescence and young adulthood, myelination includes connecting the anterior and posterior regions of the brain, a process associated with abstract thinking, executive function, and decisionmaking. ${ }^{16,17}$ These processes have been reported to be altered in adults with eating disorders. ${ }^{18-20}$

Mood and motivation may vary with protein availability, as neurotransmitters, and their receptors are built from amino acids. In particular, mood and motivation have been closely connected to neural signaling involving serotonin and dopamine. ${ }^{21}$ Both are synthesized from essential amino acids, such as tryptophan (serotonin) and phenylalanine (dopamine). Interestingly, in healthy people, acute tryptophan deficiency (ATD) can be induced using a high protein shake that contains all the other amino acids except tryptophan. ${ }^{22}$ The average healthy person shows reduced mood and increases in impulsive behaviors for several hours following the ATD protocol..$^{23,24}$ These data, in concert with other work examining serotonin and dopamine levels in the brain, ${ }^{25-27}$ support the idea that variations in the availability of these neurotransmitters may acutely alter mood and motivation. Even relatively normal levels of dietary restraint in athletes, high school, and college students have been correlated with elevations in irritability, apprehension, moodiness, depression, self-esteem, social withdrawal, and apathy, akin to those reported in the Minnesota starvation study. ${ }^{28-30}$ One study reported that women with bulimia nervosa showed similar mood shifts in response to ATD as in healthy people, and further, that those women with $\mathrm{BN}$ on selective serotonin reuptake inhibitors reported increased desires to binge following ATD. ${ }^{31}$ In both recovered and ill patients with AN compared to healthy women, ATD caused more substantial changes in serum tryptophan levels, but interestingly, the subjects with AN reported feeling less anxious during the ATD than the healthy women. ${ }^{32}$ In sum, mood changes should be anticipated in patients who regularly restrict and binge. Once nutritional deficiencies are corrected after refeeding, designing and monitoring a healthy meal plan, 
Table 3 Functional MRI studies of social behavior in eating disorders

\begin{tabular}{|c|c|c|c|}
\hline Author & Participants & Stimuli & Neural differences \\
\hline Ashworth et al ${ }^{105}$ & $\begin{array}{l}\mathrm{BN} 12 \\
\mathrm{HC} 16\end{array}$ & $\begin{array}{l}\text { Shown angry and disgusted faces as well as } \\
\text { simple shapes. }\end{array}$ & $\begin{array}{l}\text { BN with decreased precuneus activations for both } \\
\text { anger and disgust. Also decreased right amygdala } \\
\text { activation for anger. }\end{array}$ \\
\hline $\begin{array}{l}\text { McAdams and } \\
\text { Krawczyk }^{100, *}\end{array}$ & $\begin{array}{l}\text { recAN } 17 \\
\mathrm{HC} 17\end{array}$ & $\begin{array}{l}\text { Social attribution task: subjects compare } \\
\text { movements of shapes using both biological } \\
\text { (social: friends?) and nonbiological (physical: } \\
\text { same weight?) movements. }\end{array}$ & $\begin{array}{l}\text { AN group with less activation of many social cognition } \\
\text { regions, including rTPJ in biological movements. } \\
\text { No significant differences between AN and HC in } \\
\text { activations related to nonbiological condition. }\end{array}$ \\
\hline $\begin{array}{l}\text { Schulte-Ruther } \\
\text { et al }{ }^{102, *}\end{array}$ & $\begin{array}{l}\text { teenANI9 } \\
\text { teenHC } 20\end{array}$ & $\begin{array}{l}\text { Similar task as above. Scanned before } \\
\text { treatment and at discharge. I2-month clinical } \\
\text { follow-up to assess recovery. }\end{array}$ & $\begin{array}{l}\text { AN group with less activation of mPFC and temporal } \\
\text { cortex relative to HC. Hypoactivation of mPFC at } \\
\text { initial treatment associated with failure to maintain } \\
\text { weight in follow-up. }\end{array}$ \\
\hline McAdams and & $\mathrm{BN} 17$ & Same tasks as McAdams ${ }^{100}$ and $2014^{\prime \prime \prime}$ & BN subjects with differences intermediate of the AN \\
\hline Krawczyk $^{101, *}$ & $\begin{array}{l}\text { AN } 18 \\
\mathrm{HC} 18\end{array}$ & $\begin{array}{l}\text { Social attribution, social identity, and physical } \\
\text { identity tasks. }\end{array}$ & $\begin{array}{l}\text { and } \mathrm{HC} \text { subjects: significant differences in all regions } \\
\text { relative to } \mathrm{HC} \text { and save the cingulate cluster from the } \\
\text { physical identity task. }\end{array}$ \\
\hline $\begin{array}{l}\text { McAdams and } \\
\text { Krawczyk }^{\prime \prime 1, *}\end{array}$ & $\begin{array}{l}\text { recAN } 18 \\
\mathrm{HC} 18\end{array}$ & $\begin{array}{l}\text { Identity appraisal statements with social or } \\
\text { physical descriptors. }\end{array}$ & $\begin{array}{l}\mathrm{HC} \text { with more activity in cingulate for physical } \\
\text { descriptors of self and precuneus for social descriptors } \\
\text { of self relative to AN. Largest differences in } \mathrm{AACC} \\
\text { with } \mathrm{HC} \text { engaging for third person view of self but AN } \\
\text { engaging for first person view of self in social task. }\end{array}$ \\
\hline Pringle et $\mathrm{al}^{107}$ & $\begin{array}{l}\mathrm{BN} 1 \mathrm{I} \\
\mathrm{HC} 16\end{array}$ & $\begin{array}{l}\text { Presented negative social and eating disorder } \\
\text { adjectives and asked to rate self-relevance of } \\
\text { words. }\end{array}$ & $\begin{array}{l}\text { BN with less activity in precuneus, occipital area, } \\
\text { putamen, and amygdala. }\end{array}$ \\
\hline Cowdrey et al ${ }^{103, *}$ & $\begin{array}{l}\text { recAN } 16 \\
\mathrm{HC} 16\end{array}$ & Shown happy and fearful faces; decided sex. & No differences in groups. \\
\hline Fonville et al ${ }^{104, *}$ & $\begin{array}{l}\text { AN } 31 \\
\mathrm{HC} 35\end{array}$ & $\begin{array}{l}\text { Shown images of neutral, happy, and very happy } \\
\text { faces in an fMRI scanner; decided sex. }\end{array}$ & $\begin{array}{l}\text { AN with increased right fusiform gyrus for all } \\
\text { expressions. }\end{array}$ \\
\hline Miyake et al ${ }^{108}$ & $\begin{array}{l}\text { AN } 30 \\
\text { HC } 20\end{array}$ & $\begin{array}{l}\text { Asked to select most negative word (social } \\
\text { adjectives) or neutral word. }\end{array}$ & $\begin{array}{l}\text { Alexithymia negatively correlated with activation of } \\
\text { PCC and ACC. AN with increased frontal activations } \\
\text { for negative words. }\end{array}$ \\
\hline Suda et al ${ }^{109}$ & $\begin{array}{l}\text { AN } 20 \\
\text { HC } 15\end{array}$ & $\begin{array}{l}\text { Viewed images of normal weight individuals in } \\
\text { body checking behavior or a neutral body action. }\end{array}$ & $\begin{array}{l}\text { AN showed less activation of both mPFC and right } \\
\text { fusiform gyrus when compared to HC for body } \\
\text { checking compared to neutral actions. }\end{array}$ \\
\hline
\end{tabular}

Note: *Similar tasks presented adjacent to these studies.

Abbreviations: ACC, anterior cingulate cortex; $\mathrm{AN}$, anorexia nervosa; $\mathrm{AN}-\mathrm{BP}$, binge-purge anorexia nervosa; $\mathrm{AN}-\mathrm{R}$, restricting anorexia nervosa; $\mathrm{BN}$, bulimia nervosa; cing, cingulate; $\mathrm{AACC}$, dorsal anterior cingulate cortex; fMRI, functional MRI; HC, healthy controls; MRI, magnetic resonance imaging; mPFC, medial prefrontal cortex; PCC, posterior cingulate cortex; recBN, recovered bulimia nervosa; recAN, recovered anorexia nervosa; rTPJ, right temporal parietal junction; teenAN, teenagers with anorexia nervosa; teen $\mathrm{HC}$, teenagers healthy control.

and preventing binges, differences in the availability and efficacy of neurotransmitters might still impact brain function for some subjects, as common genetic variants are known to alter the metabolism and function of neurotransmitters and their receptors. ${ }^{33}$

On the structural side, both the hippocampi and anterior cingulate show reduced thickness of gray matter in patients currently with $\mathrm{AN}$, but these regions also appear to recover in size after weight restoration. ${ }^{34-36}$ Consistent with these data, neuropsychological processes associated with hippocampal function, including working memory, spatial reasoning, and set-shifting, are commonly impaired in patients currently with AN. ${ }^{37}$ Recently, cognitive remediation therapy has been developed to improve flexibility of thinking and reasoning, potentially providing stimulation to these regions in $\mathrm{AN} .{ }^{38}$
Furthermore, the anterior cingulate appears to play an essential role in self-regulation and emotional self-appraisal, and dysfunction of the anterior cingulate has also been associated with alexithymia in AN patients. ${ }^{39}$ In conclusion, reductions in the size of neural regions that are involved in both memory and emotional regulation are observed in underweight subjects.

\section{Differences in reward processing in eating disorders}

\section{Reward neurocircuitry}

To provide neuroanatomical context to this review, we have included a Neurosynth meta-analysis that highlights the neural regions most commonly identified in studies of reward (Figure 1). Five hundred and sixty studies were 

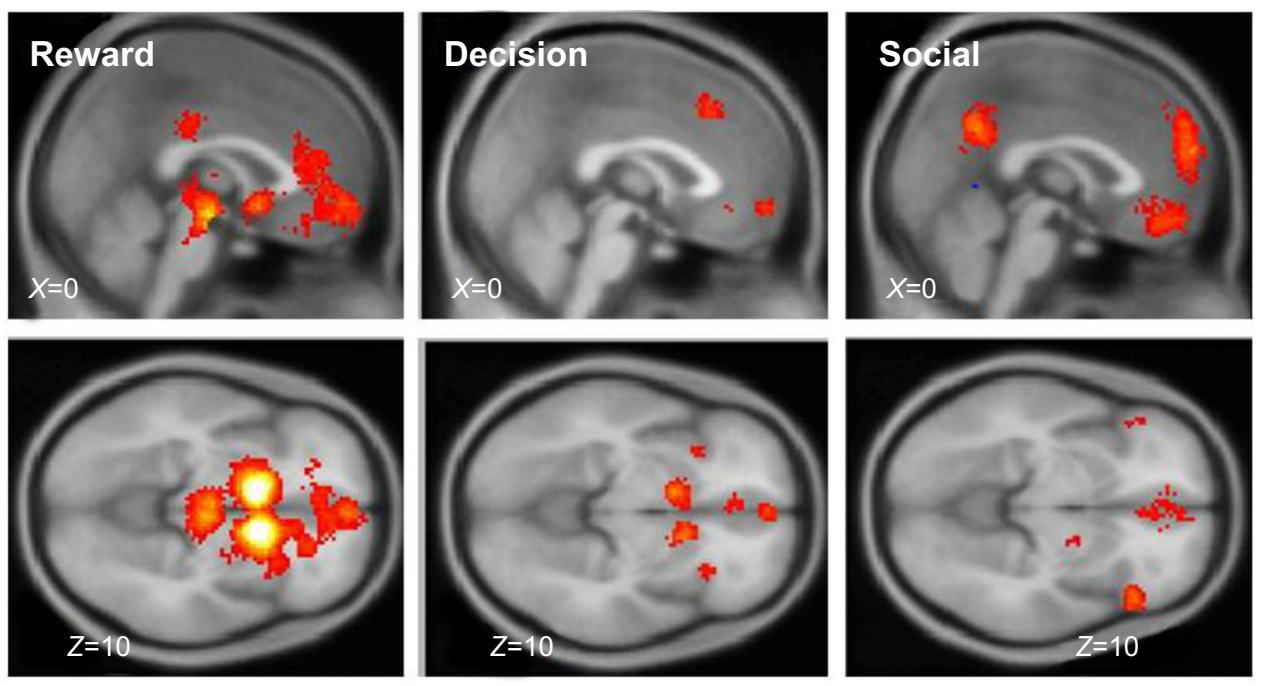

Figure I Neurosynth meta-analyses were conducted for the terms "reward," first column; "decision," second column, and "social," third column. These maps provide a visual representation of the subcortical and cortical structures engaged in studies utilizing the keywords. Each map can be examined at http://www.neurosynth.org/analyses/ terms/reward; http://www.neurosynth.org/analyses/terms/decision; and http://www.neurosynth.org/analyses/terms/social.

included in construction of the reward map, with two clusters identified $\left(P_{\mathrm{FDR}}<0.01\right)$. The first cluster was quite large ( 8,953 vox) and included bilateral nucleus accumbens, putamen, caudate, anterior insula, as well as the midbrain, the anterior cingulate and ventromedial prefrontal cortex (vmPFC). The second cluster was smaller (115 vox) and included the posterior cingulate. These are the areas that we will focus on as we consider neural differences occurring in eating disorder studies from the systematic review. Of note, the primary neural regions activated by reward studies are in subcortical (midbrain, thalamus, striatum) and limbic areas (cingulate). vmPFC is the neocortical region consistently engaged during reward studies.

Motivation is closely linked to dopamine release in nucleus accumbens, the ventral striatum, and the caudate nuclei. ${ }^{40,41}$ As nearly all behavior occurs because of motivation, disruptions related to motivation are nearly ubiquitous across mental illnesses, with both depression and addictions characterized by impairments in reward processing. ${ }^{42}$ Eating disorders commonly co-occur with both depression and substance abuse, leading to the possibility that both the hypoactivity for reward that is observed in depression and the hyperactivity for the addictive substances might occur in eating disorders. ${ }^{43-45}$

\section{Food rewards in eating disorders}

As eating itself is a primary reward process, alterations in the reward pathway function in response to food, both its taste and pictures of food, have been extensively studied in eating disorder patients. Many neuroimaging studies in eating disorders as well as obesity have focused on the brain responses to viewing and even tasting food, with additional comparisons assessing the brain responses to food when hungry and full (Table 1). The brain appears to process food differently in people with eating disorders. Most consistently, these studies have identified altered responses to food images in the ventral striatum for both AN and BN. ${ }^{46,47}$ Patients with histories of restrictive eating typically respond differently both when tasting food ${ }^{48-50}$ and when viewing pictures of food. ${ }^{49,51,52}$ In healthy people, being hungry generally increases neural responses to pictures of food, with elevated amygdala, parahippocampal, and fusiform activation during hunger. ${ }^{53}$ People with and recovered from AN (recAN), compared to $\mathrm{HC}$, show less consistent relationships between their neural responses to food images and their hunger state. ${ }^{47}$

Similarly, people with BN have shown heightened activation in response to food images in reward regions ${ }^{54}$ as well as reduced activation in response to the taste of food in the insula and medial frontal gyrus. ${ }^{55}$ Frank et al ${ }^{56}$ conducted an elegant paradigm to examine differences in expected and unexpected food reward in BN. First, they engaged a conditioning procedure to train subjects to expect a specific association (a particular visual stimuli cued either administration of sucrose or artificial saliva), but on some trials the association was altered to create an unexpected event (no sucrose given for the sucrose stimulus or sucrose given for a saliva stimulus). They found that the BN subjects showed less activation in the insula, the ventral putamen, the amygdala and the lateral orbitofrontal cortex, when that association was disrupted. This supports the idea that actual reward may be 
less important than the expectation or idea of a reward in $\mathrm{BN}$. Additionally, the responsivity of reward regions for people with BN appears to depend more strongly on emotional state with more ventral striatum responses when anticipating a positive food reward than observed in HC. ${ }^{57}$ In sum, all of these studies suggest that the anticipation and emotional values attached to the idea of food may be a stronger stimulus for the reward neurocircuitry than the administration of the actual food reward itself in $\mathrm{BN}$.

Schienle et $\mathrm{al}^{58}$ compared neural activations in reward neurocircuits for food, disgust, and neutral object images in BN, BED, normal weight $\mathrm{HC}$, and overweight $\mathrm{HC}$. They found differences in the orbitofrontal cortex in BED, and differences in the anterior cingulate and insula in $\mathrm{BN}$ in response to food images. Weygandt et $\mathrm{al}^{59}$ then examined this dataset using machine-learning techniques to diagnostically differentiate the groups. They found that differences in the responses to food images in the right and left insula cortex and ventral striatum could be used to identify which patients had BN or BED, with accuracies around $84 \%$. These differences related to food responses in the amygdala, the ventral striatum, and the anterior cingulate in both eating disorder groups, suggesting that eating disorder patients show greater engagement of cognitive control regions in response to food than healthy people.

\section{Neural responses to monetary rewards}

Understanding whether differences in reward are solely related to eating and food or extend into the neural responses to other stimuli may help determine if biological differences related to experiencing reward may underlie or contribute to development or maintenance of disordered eating behaviors. To assess this, several studies have probed the neural responses to monetary rewards in subjects with eating disorders (Table 1). In AN, many of these comparisons focus on women in weight recovery from AN (recAN) and to mitigate the effects associated with acute starvation. First, Wagner et $\mathrm{al}^{60}$ found that recAN women did not show different neural responses in the ventral striatum for positive and negative feedback, unlike healthy women. Using the same paradigm, recBN women also failed to differentiate positive and negative feedback in both the ventral striatum and the dorsal caudate. ${ }^{61}$ Bischoff-Grethe et al ${ }^{62}$ then engaged this paradigm to examine adolescent subjects with $\mathrm{AN}$, reporting that the recovered adolescents with $\mathrm{AN}$ showed more neural activation of executive and striatal regions in responses to losses. Balodis et $\mathrm{al}^{63}$ examined ventrostriatal activations in $\mathrm{BED}, \mathrm{HC}$ of normal weight, and $\mathrm{HC}$ that were overweight using a monetary incentive task. There, overweight HC differed from both other two groups, with elevated ventrostriatal activity when anticipating a reward. Most recently, the neural responses to monetary reward were examined in hungry and satiated individuals in recovery from AN and compared to those in healthy women. ${ }^{64}$ In the ventral striatum and anterior cingulate, healthy women showed greater responses to monetary reward when hungry than satiated, but the recAN group showed the opposite pattern.

Structural studies have also identified differences in the size of brain regions in the reward pathway in eating disorders. Amianto et $\mathrm{al}^{65}$ found reduced caudate size in $\mathrm{BN}$ relative to AN and HC. Similarly, Mettler et $\mathrm{al}^{66}$ reported reduced fractional anisotropy in the corona radiata in $\mathrm{BN}$, suggesting differences in the connectivity of regions related to taste and reward. Frank et $\mathrm{al}^{67}$ identified alterations in brain structure in both $\mathrm{AN}$ and $\mathrm{BN}$, with increased gray matter (GM) in medial orbitofrontal cortex and insula and reduced dorsal striatal volumes. Importantly, dorsal striatum volumes were also positively related to sensitivity to reward in both illnesses, with greater volume of the dorsal striatum corresponding to greater sensitivity to reward. Finally, Titova et $\mathrm{al}^{68}$ recently completed a meta-analysis combining nine separate studies of brain volumes in AN, identifying specific deficits in GM in the hypothalamus, caudate, and right lentiform nucleus. Brooks et $\mathrm{al}^{69}$ connected the size of the dorsolateral prefrontal cortex with dietary restraint, a finding that suggests top-down cortical feedback may serve to suppress subcortical regions related to experiencing primary rewards. In total, all of these studies suggest that reward responses may be less salient in patients with eating disorders.

\section{Differences in decision-making in eating disorders}

\section{Decision-making neurocircuitry}

Problems in decision-making can amplify the symptoms of mental disease, particularly issues with high temporal discounting for rewards, ${ }^{70}$ a common problem in addictive disorders ${ }^{71}$ and borderline personality disorder. ${ }^{72}$ The choices that an individual makes should be expected to relate to engagement of their reward pathways. One important characteristic of the reward system is a close sensitivity of the timing of reward relative to decisions and choices. ${ }^{73}$ Expectations about reward change the actual experience of reward, such that it is often more pleasurable to receive a small reward when expecting nothing than to receive a small reward when expecting a large reward. ${ }^{74}$ These studies demonstrate that cognitive expectations can modify psychological experience. 
Using Neurosynth to conduct a meta-analysis examining "decision," 569 studies were combined, resulting in an activation map with seven clusters at $P_{\text {FDR }}<0.01$ (Figure 1). Many of these clusters overlapped with areas previously identified using the reward meta-analysis: the left caudate (247 vox), the right caudate (232 vox), two clusters in the medial prefrontal cortex (63 and 85 vox), the right inferior frontal gyrus and insula (81 vox), and the left inferior frontal gyrus and insula (54 vox). Only one new region was engaged: the dorsal anterior cingulate (238 vox). In sum, activations of subcortical reward regions are closely related to decisions and decision-making, with the addition of a portion of frontal cortex.

\section{Decision-making studies in eating disorders}

Eating disorders are characterized by recurrent problems in decision-making, leading to poor behavioral choices about consuming food, both eating too little or too much, as well as overexercising and engaging in purging behaviors. The Iowa Gambling Test asks participants to select cards with different values of money on them. The objective is to choose cards with larger long-term monetary gain, and those who do are deemed to have better decision-making skills. Several researchers have examined decision-making using behavioral measures from this task in eating disorder patients. Cavedini et $\mathrm{al}^{75}$ reported that patients with $\mathrm{AN}$ have poor performance compared to $\mathrm{HC}$ but that there was no relationship between the severity of illness and the degree of poor performance. Tchanturia et al found that people with AN performed more poorly than both $\mathrm{HC}$ and recAN, and whereas recAN and $\mathrm{HC}$ did not significantly differ ${ }^{76}$ In a study comparing $\mathrm{AN}, \mathrm{BN}$, and $\mathrm{HC}, \mathrm{AN}$ and $\mathrm{BN}$ were both determined to have worse performance than $\mathrm{HC}$, but $\mathrm{AN}$ and $\mathrm{BN}$ did not differ significantly between one another. ${ }^{77-79}$ Importantly, all of this work suggests that deficits in decision making are present in ill subjects, but not in recovered subjects. Thus, poor decisionmaking may be a state-based phenomenon.

Only a few neuroimaging studies have directly accessed decision-making in eating disorders (Table 2). Decker et al ${ }^{80}$ examined decision-making in AN with fMRI at two time points, at treatment initiation and after weight-recovery, using a delayed-discounting task. Participants provided their preference about receiving some money now or a different amount of money at a future time point, allowing an individual discounting rate for each participant to be obtained, while examining neural activity during their decisions. Their data suggest that while underweight, patients with AN prefer future rewards to current rewards compared to healthy women, although the opposite phenomena occurred in the Iowa Gambling Task. ${ }^{75,76,81}$ The bias seen by Decker et al ${ }^{80}$ also normalized after weight recovery, consistent with the Iowa Gambling studies of recovered AN. ${ }^{76}$ Further, normalization of the delayed discounting behaviors corresponded to higher activity in the anterior cingulate, the ventral striatum, dorsolateral prefrontal cortex, and parietal cortex. These data suggest that starvation impacts not only subcortical reward regions but also higher cortical regions engaged to evaluate decisions.

Making decisions involves collecting and synthesizing information prior to acting on it. As such, impulsivity is a specific personality trait that sabotages decisions and frequently appears altered in psychopathology, particularly in addictions. ${ }^{82}$ Impulsivity has also been shown to be elevated in office assessments for both $\mathrm{BN}$ and $\mathrm{AN}$, binge/purge $(\mathrm{B} / \mathrm{P})$ type, ${ }^{83,84}$ and in BED. ${ }^{85,86}$ Neuroimaging studies using the Simon spatial incompatibility task to assess cognitive control identified reduced activations in the inferior frontal gyrus and anterior cingulate during response inhibition tasks in adults and adolescents with $\mathrm{BN}$ and $\mathrm{AN}, \mathrm{B} / \mathrm{P}$ type. ${ }^{87-89}$ Marsh et $\mathrm{al}^{90}$ later identified a structural difference related to symptom severity, that is, reduced gray matter in patients with $\mathrm{BN}$ in the inferior frontal gyri and temporoparietal regions. Lock et $\mathrm{al}^{91}$ also found differences in neural activations during another response inhibition task when comparing restricting $\mathrm{AN}$ with a binge-purge AN/BN group. That study found increased frontal and anterior cingulate activations in the binge-purge group, which was interpreted as inefficient processing. Impulsivity may be related to altered engagement of frontal regions as well as the bingeing and purging behaviors in EDs. Similarly, Kullmann et $\mathrm{al}^{92}$ utilized a Go/No-Go paradigm, with both food and nonfood stimuli and images of active and resting people in $\mathrm{AN}$, healthy comparison athletes, and typical healthy comparison subjects. They found that the AN group had increased prefrontal cortex responses to the active people, suggesting alterations in frontostriatal circuits for stimuli related to the illness. ${ }^{92}$ In sum, differences in several frontal regions of the brain commonly engaged in decision-making and impulsivity measures are altered in eating disorders, particularly in patients with binge and purge behaviors.

\section{Differences in social brain function in eating disorders}

\section{Social neurocircuitry}

Using Neurosynth to conduct a meta-analysis examining "social," 960 studies were combined, resulting in an activation map with 12 clusters at $P_{\text {FDR }}<0.01$ (Figure 1). 
There is considerably less overlap in the social map than the reward and decision maps showed, with social studies activating many more cortical clusters. The only overlapping regions were areas in the medial prefrontal cortex (2,177 vox) and bilateral clusters in the inferior frontal gyri and insula ( $R, 391$ vox; L, 451 vox). These regions have frequently shown alterations in both $\mathrm{BN}$ and AN. ${ }^{46,47,93}$ Other social regions included the precuneus (583 vox), bilateral temporoparietal junctions (two clusters on R, 391 vox and 60 vox; L 556 vox), bilateral amygdala ( $R, 360$ vox, L 257 vox), a cluster in the right temporal pole (572 vox), right fusiform (134 vox), and superior frontal gyrus (54 vox). Of note, these social regions include both regions engaged in reward processing (the ventral striatum, orbitofrontal cortex) and regions activated during decisionmaking (dorsolateral prefrontal cortex, inferior frontal gyri, and dorsal anterior cingulate).

Activations of many regions included in this social network can be altered based on sociocultural factors. Preferences for appearance of others ${ }^{95,96}$ appear highly malleable and can be altered over the short course of a scan to conform to what one is told about other people's preferences. Izuma and Adolphs ${ }^{97}$ showed that exposure to the preferences of peers and an anti-peer group (sex offenders) about T-shirts over the course of short, single scanner session, not only altered brain activity in the dmPFC that day, but that these changes in the dmPFC persisted for 4 months. Specific brain regions, including both the nucleus accumbens and the prefrontal cortex, appear to track and adjust the current value of potential items based on societal valuation, generally provided in the form of "this is how much your peers like this." These results are not surprising, as humans are social creatures, and nearly all of our preferences for whom we socialize with, and what our beliefs and values are, emerge based on interactions with other people.

Eating disorder (ED) behaviors have been related to the adoption of Western values and the exposure to Western media, supporting an idea that brain differences related to social factors might be present in this illness. Anne Becker ${ }^{98}$ studied Fijian girls (mean age 17) in 1995 and 1998. The first wave was surveyed in 1995 when Western television had been accessible on the island for less than a month. The 1998 wave had been exposed to television for 3 years and had radically different attitudes regarding body image and eating. The percentage of girls purging to achieve weight goals was $0 \%$ in 1995 to $11.3 \%$ in $1998 .{ }^{98}$ In subsequent work, Becker et al found that even indirect exposure to television, through peers with access to television, impacted the adolescent's beliefs related to the ideal female body image and social identity. ${ }^{99}$

\section{Social neuroimaging studies in eating disorders}

Several imaging studies have examined neural responses to social stimuli in EDs (Table 3). During imaging tasks probing general social behaviors, subjects with $\mathrm{AN}$ and $\mathrm{BN}$ have shown reduced modulation of the inferior frontal gyri, the medial temporal gyrus, the temporoparietal junctions, and the medial prefrontal cortex. ${ }^{100-102}$ Modulation of the medial prefrontal cortex in currently ill adolescents with AN has even been associated with outcomes after treatment for the disorder, ${ }^{102}$ supporting the idea that social brain function may be an important consideration in predicting outcomes following treatment.

One basic social-emotional task involves intuiting other people's emotional states by viewing faces. Cowdrey et al ${ }^{103}$ presented emotional faces to 16 weight-recovered AN subjects and $16 \mathrm{HC}$ and found no neural differences. In contrast, using a similar task but with 31 underweight AN subjects and $31 \mathrm{HC}$, Fonville et $\mathrm{l}^{104}$ found elevated responses in the fusiform gyrus in the AN subjects while viewing neutral, happy, and very happy expressions relative to healthy women. Ashworth et $\mathrm{al}^{105}$ found reduced neural responses in the precuneus for angry and disgusting expression in subjects with $\mathrm{BN}$ compared to healthy women, as well as reduced amygdala activation to angry expressions. In concert, these data suggest that the patients currently meeting criteria for eating disorders are more likely to show altered neural responses to basic social and emotional stimuli than patients recovered from an eating disorder.

Considering social and body image descriptive adjectives related to oneself or others are a social cognitive task that can engage neural regions related to self-knowledge, typically the midline cortical structures. ${ }^{106}$ Pringle et al ${ }^{107}$ reported reduced activation in the precuneus, occipital area, putamen, and amygdala in response to rating the relevance of negative social adjectives in BN. Miyake et $\mathrm{al}^{108}$ found that AN subjects showed elevated frontal activations for negative social adjectives relative to the $\mathrm{HC}$ subjects. Further, the amount of alexithymia in the AN group correlated with the activation of both the anterior and posterior cingulate cortex, suggesting that emotional processing of negative stimuli in these self-referential neural regions may be specifically impaired in AN. Suda et $\mathrm{al}^{109}$ also observed reduced activation in the medial prefrontal cortex and right fusiform gyrus in an AN group, in response to viewing individuals engaging in body checking, an ED behavior. All of these studies suggest that 
self-knowledge may be specifically altered in EDs, consistent with the recently proposed idea that our self may be largely defined by what is rewarding to us. ${ }^{110}$

We examined the neural differences in adults with AN and BN using a pair of self-appraisal tasks. ${ }^{101,111}$ Subjects were asked to consider the validity of statements about themselves, their friend or their friend's opinion of themselves. Two versions of the task were presented; in the social version, the prompt was a social adjective such as "kind," whereas in the physical version, the prompt was a physical descriptor such as "white teeth." One interesting observation was that the patient groups showed more activity in the precuneus for physical descriptors related to their friend or friend's opinion whereas the healthy subjects showed much stronger activity in the precuneus when considering the social characteristics of their friend. A recent meta-analysis has identified activations of the precuneus as primarily related to other processing. ${ }^{112}$ These data suggest that the patients with eating disorders show less neural responsivity for social descriptors than for physical descriptors. Interestingly, Cabanis et al ${ }^{113}$ recently examined positive and negative social attributions in healthy people and identified the posterior precuneus as a region specifically associated with positive self-attributions. In concert, these data suggest that there may be significant differences in neural function of the precuneus in relation to both self and other processing in patients with eating disorders.

\section{Conclusion}

Eating disorders are complex psychiatric illnesses that include alterations in the neural systems related to reward, decision-making, and social processing. At this point, we cannot determine if the neural differences identified in eating disorders cause or are caused by the eating disorder. This does not lessen the importance of understanding the effects of these differences in the patients. First, providers must continually reiterate the expected neurobiological changes in brain function that relate to impaired nutrition: fatigue, concentration, mood swings, insomnia, impulsivity, anhedonia and learning impairments are the expected sequelae of starvation. ${ }^{28,29}$ Furthermore, our ability to target treatments should consider identified neural differences. Ideally, research will be conducted examining the impact of treatments on neural function of these pathways and regions, to help identify the changes leading to recovery.

\section{Treatment implications: food rewards}

One major translational result emerging across these studies is that people with eating disorders show less of a connection between their physiological need for food and their reward pathway responses to food than healthy people. Eating disorders appear to disrupt both hunger and hedonic responses to food. This suggests that treatments that do not require patients to identify appropriate amounts of food based on internal cueing are more likely to be more effective, as the internal cueing related to hunger and satiety is disrupted. This is consistent with most inpatient and partial hospital programs for $\mathrm{AN}$ and $\mathrm{BN}$ in which a dietician generally creates a meal plan for the patients as well as outpatient family therapy in which the authority to select appropriate foods and their amounts is given to the parents or caregivers. ${ }^{14-116}$ For $\mathrm{BN}$ and $\mathrm{BED}$, one common approach across most therapies and treatments involves development of strategies that limit access to foods that the patients associate with binge eating. Another important translational consideration are the findings that neural responses to food stimuli depend on the emotional state of eating disorder patients. ${ }^{57}$ Thompson-Brenner et al ${ }^{117}$ recently reported that the improvement of depressive symptoms 4 weeks after the start of treatment of BN was as robust a predictor of success in treatment as the improvement in purging symptoms at 4 weeks. This clinical study supports the importance of mood symptoms as a possible mediator of eating disorder behaviors, just as observed in neuroimaging activations described in Bohon and Stice. ${ }^{57}$

\section{Treatment implications: food rewards and social pressures}

Excitingly, recent work examining food preferences in healthy subjects has shown that immediate feedback about peer preferences for specific foods alters both the subject's reported preferences for specific foods and neural responses to images of that food in the nucleus accumbens (NA) and vmPFC. Nook and Zaki ${ }^{118}$ asked college students to rate how much they liked a variety of both healthy and hedonic foods. After each rating, they were told the "average college student" rating for that food. They then repeated the task without the immediate peer feedback. Subjects' original ratings shifted toward that of the peers, with changes in neural activations in both the NA and vmPFC. These are regions that are both part of the "reward" pathways identified in the Neurosynth map (Figure 1). This study demonstrates that peer values related to food preference can significantly and immediately alter both subcortical (NA) and cortical (vmPFC) activations.

We would like to consider this study in the context of the development and treatment of eating disorders. In concert with the proliferation of eating disorder support, social 
media, and eating disorder promotion groups on the internet, people with eating disorders seek out information related to the valuation of both hedonic and healthy foods. ${ }^{119,120}$ These different experiences related to peer valuations for food in eating disorder subjects and healthy comparison subjects likely contribute to the different neural responses in valuation regions in eating disorders. ${ }^{47,121}$ Furthermore, the malleability of valuation of food observed in healthy people suggests one important process during eating disorder treatments may be assistance in helping patients formulate new values and expectations surrounding food. As a caution, these data also suggest that exposure to eating disorder beliefs about food from peers (eg, all fats are unhealthy) might intensify some symptoms of this disease.

\section{Treatment implications: reward, decisions and social evaluations}

The studies of reward (Table 1) also suggest that the subcortical levels of reward responses may be less salient in response to the direct food stimuli in patients who have had eating disorders. Unfortunately, reward defines much of people's lives, and we choose to do things that are rewarding for us. For people with eating disorders, direction in life may be more challenging, given reduced saliency of signals from their reward pathways. From a translational perspective, treatments that improve reward signaling may lead to improved outcomes. These treatments might include psychotherapeutic treatments to identify and amplify reward signals, pharmaceutical strategies to enhance neurotransmitters involved in reward, or targeted regional brain stimulation. For example, repetitive transcranial magnetic stimulation to dorsomedial prefrontal cortex appears most effective for the subset of depressed patients who also show high levels of anhedonia, a construct specifically related to the experience of reward. ${ }^{122}$ A recent case report describes a patient with both $\mathrm{BN}$ and depression who underwent repetitive transcranial magnetic stimulation for depression but had rapid remission of bulimia symptoms following that procedure. ${ }^{123}$ Assessment of anhedonia may provide a useful clinical method to assess reward pathway function in eating disorders. However, more research is needed to relate psychological measures, such as anhedonia, with both eating disorder behaviors, such as purging, and the dysfunction of specific neurocircuitry.

Psychosocial factors may contribute substantially to the alterations in decision-making and social brain differences demonstrated in eating disorders. The largest differences we observed in both $\mathrm{AN}$ and $\mathrm{BN}$ subjects in comparison to $\mathrm{HC}$ subjects, during a social identity task were in the dorsal anterior cingulate, and corresponded to the difference between subjects thinking about themselves from another person's perspective compared to thinking about themselves from their own perspective..$^{101,111}$ Recently, activations of that region, the dorsal anterior cingulate, were specifically related to the difficulty of performing a task in healthy people. ${ }^{124}$ In considering the relationship between this part of the brain and its role in decision-making and choice difficulty, these data suggest that the patients with eating disorders may find the process of evaluating themselves to be a more challenging task than considering other people's views. From a translational treatment perspective, these data suggest that helping eating disorder patients with sociocultural evaluations related to human social behaviors rather than physical appearance may facilitate recovery. Similarly, imaging studies that showing deficits in social perception in patients currently with eating disorders support a role for therapies with some focus on social relationships in eating disorders, such as family therapy, couples, and mentalization-based therapy. ${ }^{125-127}$

\section{Treatment implications: summary}

In conclusion, eating disorders appear to include changes in the neural systems that mediate reward responses, decisionmaking, and social behaviors. As such, treatments are likely to require individualization based on the specific constellation of symptoms that each patient expresses. Different reward values for different experiences likely lead to different choices. Consider people who choose to stay home, investing in amenities for their home, in contrast to people who love to travel, investing in the expense of airfare and hotels. In eating disorders, decision-making and social behaviors may reinforce eating disordered behaviors due to alterations in the reward values that have become associated with food and appearance. Cognitive treatments of EDs likely function at least in part by facilitating the normalization and acceptance of consistent healthy eating patterns while simultaneously working to devalue judgments that one's worth is based on appearance.

One cognitive measure that may be worth further investigation is self-esteem. Low self-esteem has been proposed as a prerequisite for the development of an ED, ${ }^{128}$ appears to serve as a prognostic factor for the development of EDs, ${ }^{129}$ can persist even following recovery from $\mathrm{BN},{ }^{130}$ and improvements in self-esteem are associated with recovery and completion of treatment. ${ }^{131,132}$ Evidence from healthy women is accumulating that self-esteem may relate to the engagement of frontal brain regions during social tasks. In healthy women, 
Mischner et al have found that women with low self-esteem are both more attentive to and alter their beliefs more after exposure to sexually objectifying material ${ }^{133}$ and react less if given norm-challenging education prior to the exposure. ${ }^{134}$ Somerville et al ${ }^{135}$ have also demonstrated, in healthy participants, that activity in the dorsal anterior cingulate cortex and vmPFC are linearly responsive to positive feedback, but only for subjects with low self-esteem, suggesting that these regions are particularly important for identifying and evaluating societal expectations. Fascinatingly, these regions were engaged by all three of the neural systems examined here: reward, decision, and social processing (Figure 1), and differences in these regions are observed in many studies of both $\mathrm{AN}$ and BN. ${ }^{80,87,92,101,111,136-141}$ Researchers examining brain function in concert with recovery from eating disorders should include measures of self-esteem in concert with clinical symptoms to clarify how neural differences may be related to self-esteem.

Understanding the role of neurobiological processes in mediating psychosocial responsivity may also help in designing and executing more efficient treatments for EDs. Recently, real-time neurofeedback techniques have trained subjects with depression to modulate the amygdala, improving depressive symptoms, ${ }^{142}$ and healthy subjects have been able to enhance neural activity in the hypothalamus and frontopolar cortex associated with affliative emotions. ${ }^{143}$ In the future, real-time neurofeedback may enable targeted treatments for specific symptoms of eating disorders. For example, real-time modulation of the vmPFC during selfevaluation might be assessed as an adjuctive treatment for eating disorder patients with low self-esteem. Subjects with difficulties in reacting to food stimuli might benefit from real-time modulation of the ventral striatum in response to food stimuli. However, more research is needed to better characterize how psychological and cognitive measures are associated with neural pathway dysfunctions, and also to relate these measures and neural dysfunctions to treatment and recovery. These types of studies may lead to improvements in the ability to identify, characterize, and treat eating disorders.

\section{Acknowledgments}

CJM has support from an NIMH K23 MH093684, a 2012 NARSAD Young Investigator Award from the Brain and Behavior Foundation, and a Junior Investigator Award from the Children's Clinical Research Advisory Board at Children's Medical Center, Dallas, TX, USA.

\section{Disclosure}

The authors report no conflicts of interest in this work.

\section{References}

1. Smink FR, van Hoeken D, Hoek HW. Epidemiology of eating disorders: incidence, prevalence and mortality rates. Curr Psychiatry Rep. 2012; 14(4):406-414.

2. Weiselberg EC, Gonzalez M, Fisher M. Eating disorders in the twentyfirst century. Minerva Ginecol. 2011;63(6):531-545.

3. Bulik CM, Sullivan PF, Tozzi F, Furberg H, Lichtenstein P, Pedersen NL. Prevalence, heritability, and prospective risk factors for anorexia nervosa. Arch Gen Psychiatry. 2006;63(3):305-312.

4. Berkman ND, Bulik CM, Brownley KA, et al. Management of eating disorders. Evid Rep Technol Assess (Full Rep). 2006;135:1-166.

5. Shapiro JR, Berkman ND, Brownley KA, Sedway JA, Lohr KN, Bulik CM. Bulimia nervosa treatment: a systematic review of randomized controlled trials. Int J Eat Disord. 2007;40(4):321-336.

6. Bulik CM, Berkman ND, Brownley KA, Sedway JA, Lohr KN. Anorexia nervosa treatment: a systematic review of randomized controlled trials. Int J Eat Disord. 2007;40(4):310-320.

7. Brownley KA, Berkman ND, Sedway JA, Lohr KN, Bulik CM. Binge eating disorder treatment: a systematic review of randomized controlled trials. Int J Eat Disord. 2007;40(4):337-348.

8. Yarkoni T, Poldrack RA, Nichols TE, Van Essen DC, Wager TD. Large-scale automated synthesis of human functional neuroimaging data. Nat Methods. 2011;8(8):665-670.

9. Crowe TC. Safety of low-carbohydrate diets. Obes Rev. 2005;6(3): 235-245.

10. Olson RE. Is it wise to restrict fat in the diets of children? $J$ Am Diet Assoc. 2000;100(1):28-32.

11. Jauregui Lobera I, Bolanos Rios P. Choice of diet in patients with anorexia nervosa. Nutr Hosp. 2009;24(6):682-687.

12. Segura-Garcia C, De Fazio P, Sinopoli F, De Masi R, Brambilla F. Food choice in disorders of eating behavior: correlations with the psychopathological aspects of the diseases. Compr Psychiatry. 2014;55(5): 1203-1211.

13. van der Ster Wallin G, Norring C, Holmgren S. Binge eating versus nonpurged eating in bulimics: is there a carbohydrate craving after all? Acta Psychiatr Scand. 1994;89(6):376-381.

14. O'Muircheartaigh J, Dean DC 3rd, Ginestet CE, et al. White matter development and early cognition in babies and toddlers. Hum Brain Mapp. 2014;35(9):4475-4487.

15. Goldman-Rakic PS. Development of cortical circuitry and cognitive function. Child Dev. 1987;58(3):601-622.

16. Kelly AM, Di Martino A, Uddin LQ, et al. Development of anterior cingulate functional connectivity from late childhood to early adulthood. Cereb Cortex. 2009;19(3):640-657.

17. Tamnes CK, Ostby Y, Fjell AM, Westlye LT, Due-Tonnessen P, Walhovd KB. Brain maturation in adolescence and young adulthood: regional age-related changes in cortical thickness and white matter volume and microstructure. Cereb Cortex. 2010;20(3):534-548.

18. Weider S, Indredavik MS, Lydersen S, Hestad K. Neuropsychological function in patients with anorexia nervosa or bulimia nervosa. Int J Eat Disord. 2015;48(4):397-405.

19. Zakzanis KK, Campbell Z, Polsinelli A. Quantitative evidence for distinct cognitive impairment in anorexia nervosa and bulimia nervosa. J Neuropsychol. 2010;4(pt 1):89-106.

20. Danner UN, Sanders N, Smeets PA, et al. Neuropsychological weaknesses in anorexia nervosa: set-shifting, central coherence, and decision making in currently ill and recovered women. Int J Eat Disord. 2012; 45(5):685-694.

21. Wallin MS, Rissanen AM. Food and mood: relationship between food, serotonin and affective disorders. Acta Psychiatr Scand Suppl. 1994;377:36-40. 
22. Young SN. Methodology and interpretation of acute tryptophan depletion studies. Acta Psychiatr Scand. 2014;129(2):156.

23. Young SN. Acute tryptophan depletion in humans: a review of theoretical, practical and ethical aspects. J Psychiatry Neurosci. 2013;38(5): 294-305.

24. Dougherty DM, Richard DM, James LM, Mathias CW. Effects of acute tryptophan depletion on three different types of behavioral impulsivity. Int J Tryptophan Res. 2010;3:99-111.

25. Pandey GN. Biological basis of suicide and suicidal behavior. Bipolar Disord. 2013;15(5):524-541.

26. Delgado PL. Monoamine depletion studies: implications for antidepressant discontinuation syndrome. J Clin Psychiatry. 2006;67(Suppl 4):22-26.

27. Booij L, Van der Does AJ, Riedel WJ. Monoamine depletion in psychiatric and healthy populations: review. Mol Psychiatry. 2003;8(12): 951-973.

28. Hagan MM, Tomaka J, Moss DE. Relation of dieting in college and high school students to symptoms associated with semi-starvation. $J$ Health Psychol. 2000;5(1):7-15.

29. Keys A. Human starvation and its consequences. J Am Diet Assoc. 1946;22:582-587.

30. Caulfield MJ, Karageorghis CI. Psychological effects of rapid weight loss and attitudes towards eating among professional jockeys. J Sports Sci. 2008;26(9):877-883.

31. Bruce KR, Steiger H, Young SN, Kin NM, Israel M, Levesque M. Impact of acute tryptophan depletion on mood and eating-related urges in bulimic and nonbulimic women. J Psychiatry Neurosci. 2009;34(5): 376-382.

32. Kaye WH, Barbarich NC, Putnam K, et al. Anxiolytic effects of acute tryptophan depletion in anorexia nervosa. Int $J$ Eat Disord. 2003;33(3):257-267; discussion 268-270.

33. Gatt JM, Burton KL, Williams LM, Schofield PR. Specific and common genes implicated across major mental disorders: a review of metaanalysis studies. J Psychiatr Res. 2015;60:1-13.

34. Connan F, Murphy F, Connor SE, et al. Hippocampal volume and cognitive function in anorexia nervosa. Psychiatry Res. 2006;146(2):117-125.

35. Mainz V, Schulte-Rüther M, Fink GR, Herpertz-Dahlmann B, Konrad K. Structural brain abnormalities in adolescent anorexia nervosa before and after weight recovery and associated hormonal changes. Psychosom Med. 2012;74(6):574-582.

36. McCormick LM, Keel PK, Brumm MC, et al. Implications of starvationinduced change in right dorsal anterior cingulate volume in anorexia nervosa. Int J Eat Disord. 2008;41(7):602-610.

37. Tchanturia K, Davies H, Roberts M, et al. Poor cognitive flexibility in eating disorders: examining the evidence using the Wisconsin Card Sorting Task. PLoS One. 2012;7(1):e28331.

38. Lindvall Dahlgren C, Ro O. A systematic review of cognitive remediation therapy for anorexia nervosa - development, current state and implications for future research and clinical practice. J Eat Disord. 2014;2(1):26.

39. Miyake Y, Okamoto Y, Onoda K, Shirao N, Mantani T, Yamawaki S Neural correlates of alexithymia in response to emotional stimuli: a study of anorexia nervosa patients. Hiroshima J Med Sci. 2009;58(1):1-8.

40. Bressan RA, Crippa JA. The role of dopamine in reward and pleasure behaviour - review of data from preclinical research. Acta Psychiatr Scand Suppl. 2005;427:14-21.

41. Taber KH, Black DN, Porrino LJ, Hurley RA. Neuroanatomy of dopamine: reward and addiction. $J$ Neuropsychiatry Clin Neurosci. 2012;24(1):1-4.

42. Baskin-Sommers AR, Foti D. Abnormal reward functioning across substance use disorders and major depressive disorder: considering reward as a transdiagnostic mechanism. Int J Psychophysiol. 2015.

43. Touchette E, Henegar A, Godart NT, et al. Subclinical eating disorders and their comorbidity with mood and anxiety disorders in adolescent girls. Psychiatry Res. 2011;185(1-2):185-192.

44. Root TL, Pisetsky EM, Thornton L, Lichtenstein P, Pedersen NL, Bulik CM. Patterns of co-morbidity of eating disorders and substance use in Swedish females. Psychol Med. 2010;40(1):105-115.
45. Godart NT, Perdereau F, Rein Z, Berthoz S, Wallier J, Jeammet P, Flament MF. Comorbidity studies of eating disorders and mood disorders. Critical review of the literature. J Affect Disord. 2007;97(1-3): $37-49$

46. Kaye WH, Wagner A, Fudge JL, Paulus M. Neurocircuity of eating disorders. Curr Top Behav Neurosci. 2011;6:37-57.

47. Phillipou A, Rossell SL, Castle DJ. The neurobiology of anorexia nervosa: a systematic review. Aust N Z J Psychiatry. 2014;48(2):128-152.

48. Wagner A, Aizenstein H, Mazurkewicz L, et al. Altered insula response to taste stimuli in individuals recovered from restricting-type anorexia nervosa. Neuropsychopharmacology. 2008;33(3):513-523.

49. Cowdrey FA, Park RJ, Harmer CJ, McCabe C. Increased neural processing of rewarding and aversive food stimuli in recovered anorexia nervosa. Biol Psychiatry. 2011;70(8):736-743.

50. Oberndorfer TA, Frank GK, Simmons AN, et al. Altered insula response to sweet taste processing after recovery from anorexia and bulimia nervosa. Am J Psychiatry. 2013;170(10):1143-1151.

51. Brooks SJ, O’Daly O, Uher R, et al. Thinking about eating food activates visual cortex with reduced bilateral cerebellar activation in females with anorexia nervosa: an fMRI study. PLoS One. 2012;7(3):e34000.

52. Holsen LM, Lawson EA, Blum J, et al. Food motivation circuitry hypoactivation related to hedonic and nonhedonic aspects of hunger and satiety in women with active anorexia nervosa and weight-restored women with anorexia nervosa. J Psychiatry Neurosci. 2012;37(5): $322-332$.

53. LaBar KS, Gitelman DR, Parrish TB, Kim YH, Nobre AC, Mesulam MM. Hunger selectively modulates corticolimbic activation to food stimuli in humans. Behav Neurosci. 2001;115(2):493-500.

54. Brooks SJ, O'Daly OG, Uher R, et al. Differential neural responses to food images in women with bulimia versus anorexia nervosa. PLoS One. 2011;6(7):e22259.

55. Bohon C, Stice E. Reward abnormalities among women with full and subthreshold bulimia nervosa: a functional magnetic resonance imaging study. Int J Eat Disord. 2011;44(7):585-595.

56. Frank GK, Reynolds JR, Shott ME, O'Reilly RC. Altered temporal difference learning in bulimia nervosa. Biol Psychiatry. 2011;70(8): 728-735.

57. Bohon C, Stice E. Negative affect and neural response to palatable food intake in bulimia nervosa. Appetite. 2012;58(3):964-970.

58. Schienle A, Schafer A, Hermann A, Vaitl D. Binge-eating disorder: reward sensitivity and brain activation to images of food. Biol Psychiatry. 2009;65(8):654-661.

59. Weygandt M, Schaefer A, Schienle A, Haynes JD. Diagnosing different binge-eating disorders based on reward-related brain activation patterns. Hum Brain Mapp. 2012;33(9):2135-2146.

60. Wagner A, Aizenstein H, Venkatraman VK, et al. Altered reward processing in women recovered from anorexia nervosa. Am J Psychiatry. 2007;164(12):1842-1849.

61. Wagner A, Aizenstein H, Venkatraman VK, et al. Altered striatal response to reward in bulimia nervosa after recovery. Int J Eat Disord. 2010;43(4):289-294.

62. Bischoff-Grethe A, McCurdy D, Grenesko-Stevens E, et al. Altered brain response to reward and punishment in adolescents with anorexia nervosa. Psychiatry Res. 2013;214(3):331-340.

63. Balodis IM, Kober H, Worhunsky PD, et al. Monetary reward processing in obese individuals with and without binge eating disorder. Biol Psychiatry. 2013;73(9):877-886.

64. Wierenga CE, Bischoff-Grethe A, Melrose AJ, et al. Hunger does not motivate reward in women remitted from anorexia nervosa. Biol Psychiatry. 2015;77(7):642-652.

65. Amianto F, Caroppo P, D'Agata F, et al. Brain volumetric abnormalities in patients with anorexia and bulimia nervosa: a voxel-based morphometry study. Psychiatry Res. 2013;213(3):210-216.

66. Mettler LN, Shott ME, Pryor T, Yang TT, Frank GK. White matter integrity is reduced in bulimia nervosa. The Int J Eat Disord. 2013;46(3): 264-273. 
67. Frank GK, Shott ME, Hagman JO, Mittal VA. Alterations in brain structures related to taste reward circuitry in ill and recovered anorexia nervosa and in bulimia nervosa. Am J Psychiatry. 2013;170(10): $1152-1160$.

68. Titova OE, Hjorth OC, Schioth HB, Brooks SJ. Anorexia nervosa is linked to reduced brain structure in reward and somatosensory regions: a meta-analysis of VBM studies. BMC Psychiatry. 2013;13:110.

69. Brooks SJ, Barker GJ, O'Daly OG, et al. Restraint of appetite and reduced regional brain volumes in anorexia nervosa: a voxel-based morphometric study. BMC Psychiatry. 2011;11:179.

70. Story GW, Vlaev I, Seymour B, Darzi A, Dolan RJ. Does temporal discounting explain unhealthy behavior? A systematic review and reinforcement learning perspective. Front Behav Neurosci. 2014;8:76.

71. MacKillop J, Amlung MT, Few LR, Ray LA, Sweet LH, Munafo MR. Delayed reward discounting and addictive behavior: a meta-analysis. Psychopharmacology. 2011;216(3):305-321.

72. Mak AD, Lam LC. Neurocognitive profiles of people with borderline personality disorder. Curr Opin Psychiatry. 2013;26(1):90-96.

73. Bermudez MA, Schultz W. Timing in reward and decision processes. Philos Trans R Soc Lond B Biol Sci. 2014;369(1637):20120468.

74. Abler B, Herrnberger B, Gron G, Spitzer M. From uncertainty to reward: BOLD characteristics differentiate signaling pathways. BMC Neurosci. 2009; 10:154.

75. Cavedini P, Zorzi C, Bassi T, et al. Decision-making functioning as a predictor of treatment outcome in anorexia nervosa. Psychiatry Res. 2006;145(2-3):179-187.

76. Tchanturia K, Liao PC, Uher R, Lawrence N, Treasure J, Campbell IC. An investigation of decision making in anorexia nervosa using the Iowa Gambling Task and skin conductance measurements. J Int Neuropsychol Soc. 2007;13(4):635-641.

77. Boeka AG, Lokken KL. The Iowa Gambling Task as a measure of decision making in women with bulimia nervosa. $J$ Int Neuropsychol Soc. 2006;12(5):741-745.

78. Brand M, Franke-Sievert C, Jacoby GE, Markowitsch HJ, TuschenCaffier B. Neuropsychological correlates of decision making in patients with bulimia nervosa. Neuropsychology. 2007;21(6):742-750.

79. Liao PC, Uher R, Lawrence N, et al. An examination of decision making in bulimia nervosa. J Clin Exp Neuropsychol. 2009;31(4):455-461.

80. Decker JH, Figner B, Steinglass JE. On weight and waiting: delay discounting in anorexia nervosa pretreatment and posttreatment. Biol Psychiatry. In press 2014.

81. Roberts ME, Tchanturia K, Stahl D, Southgate L, Treasure J. A systematic review and meta-analysis of set-shifting ability in eating disorders. Psychol Med. 2007;37(8):1075-1084.

82. Stevens L, Verdejo-Garcia A, Goudriaan AE, Roeyers H, Dom G, Vanderplasschen W. Impulsivity as a vulnerability factor for poor addiction treatment outcomes: a review of neurocognitive findings among individuals with substance use disorders. J Subst Abuse Treat. 2014;47(1):58-72.

83. Rosval L, Steiger H, Bruce K, Israel M, Richardson J, Aubut M. Impulsivity in women with eating disorders: problem of response inhibition, planning, or attention? Int J Eat Disord. 2006;39(7):590-593.

84. Southgate L, Tchanturia K, Treasure J. Information processing bias in anorexia nervosa. Psychiatry Res. 2008;160(2):221-227.

85. Hege MA, Stingl KT, Kullmann S, et al. Attentional impulsivity in binge eating disorder modulates response inhibition performance and frontal brain networks. Int J Obes. 2015;39(2):353-360.

86. Schag K, Teufel M, Junne F, et al. Impulsivity in binge eating disorder: food cues elicit increased reward responses and disinhibition. PLoS One. 2013;8(10):e76542.

87. Marsh R, Steinglass JE, Gerber AJ, et al. Deficient activity in the neural systems that mediate self-regulatory control in bulimia nervosa. Arch Gen Psychiatry. 2009;66(1):51-63.

88. Marsh R, Horga G, Wang Z, et al. An FMRI study of self-regulatory control and conflict resolution in adolescents with bulimia nervosa. Am J Psychiatry. 2011;168(11):1210-1220.
89. Uher R, Murphy T, Brammer MJ, et al. Medial prefrontal cortex activity associated with symptom provocation in eating disorders. Am J Psychiatry. 2004;161(7):1238-1246.

90. Marsh R, Stefan M, Bansal R, Hao X, Walsh BT, Peterson BS. Anatomical characteristics of the cerebral surface in bulimia nervosa. Biol Psychiatry. 2015;77(7):616-623.

91. Lock J, Garrett A, Beenhakker J, Reiss AL. Aberrant brain activation during a response inhibition task in adolescent eating disorder subtypes. Am J Psychiatry. 2011;168(1):55-64.

92. Kullmann $\mathrm{S}$, Giel $\mathrm{KE}, \mathrm{Hu} \mathrm{X}$, et al. Impaired inhibitory control in anorexia nervosa elicited by physical activity stimuli. Soc Cogn Affect Neurosci. 2014;9(7):917-923.

93. Lipsman N, Woodside DB, Lozano AM. Neurocircuitry of limbic dysfunction in anorexia nervosa. Cortex. 2015;62:109-118.

94. Zhu Y, Hu X, Wang J, Chen J, Guo Q, Li C, Enck P. Processing of food, body and emotional stimuli in anorexia nervosa: a systematic review and meta-analysis of functional magnetic resonance imaging studies. Eur Eat Disord Rev. 2012;20(6):439-450.

95. Klucharev V, Hytonen K, Rijpkema M, Smidts A, Fernandez G. Reinforcement learning signal predicts social conformity. Neuron. 2009;61(1):140-151.

96. Zaki J, Schirmer J, Mitchell JP. Social influence modulates the neural computation of value. Psychol Sci. 2011;22(7):894-900.

97. Izuma K, Adolphs R. Social manipulation of preference in the human brain. Neuron. 2013;78(3):563-573.

98. Becker AE. Television, disordered eating, and young women in Fiji: negotiating body image and identity during rapid social change. Cult Med Psychiatry. 2004;28(4):533-559.

99. Becker AE, Fay KE, Agnew-Blais J, Khan AN, Striegel-Moore RH, Gilman SE. Social network media exposure and adolescent eating pathology in Fiji. Br J Psychiatry. 2011;198(1):43-50.

100. McAdams CJ, Krawczyk DC. Impaired neural processing of social attribution in anorexia nervosa. Psychiatry Res. 2011;194(1): 54-63.

101. McAdams CJ, Krawczyk DC. Neural responses during social and selfknowledge tasks in bulimia nervosa. Front Psychiatry. 2013;4:103.

102. Schulte-Ruther M, Mainz V, Fink GR, Herpertz-Dahlmann B, Konrad K. Theory of mind and the brain in anorexia nervosa: relation to treatment outcome. JAm Acad Child Adolesc Psychiatry. 2012;51(8): 832-841.

103. Cowdrey FA, Harmer CJ, Park RJ, McCabe C. Neural responses to emotional faces in women recovered from anorexia nervosa. Psychiatry Res. 2012;201(3):190-195.

104. Fonville L, Giampietro V, Surguladze S, Williams S, Tchanturia K. Increased BOLD signal in the fusiform gyrus during implicit emotion processing in anorexia nervosa. Neuroimage Clin. 2014;4: 266-273.

105. Ashworth F, Pringle A, Norbury R, Harmer CJ, Cowen PJ, Cooper MJ. Neural response to angry and disgusted facial expressions in bulimia nervosa. Psychol Med. 2011;41(11):2375-2384.

106. Northoff G, Heinzel A, de Greck M, Bermpohl F, Dobrowolny H, Panksepp J. Self-referential processing in our brain - a meta-analysis of imaging studies on the self. Neuroimage. 2006;31(1):440-457.

107. Pringle A, Ashworth F, Harmer CJ, Norbury R, Cooper MJ. Neural correlates of the processing of self-referent emotional information in bulimia nervosa. Neuropsychologia. 2011;49(12):3272-3278.

108. Miyake Y, Okamoto Y, Onoda K, Shirao N, Okamoto Y, Yamawaki S. Brain activation during the perception of stressful word stimuli concerning interpersonal relationships in anorexia nervosa patients with high degrees of alexithymia in an fMRI paradigm. Psychiatry Res. 2012;201(2):113-119.

109. Suda M, Brooks SJ, Giampietro V, et al. Functional neuroanatomy of body checking in people with anorexia nervosa. Int J Eat Disord. 2013;46(7):653-662.

110. Northoff G, Hayes DJ. Is our self nothing but reward? Biol Psychiatry. 2011;69(11):1019-1025. 
111. McAdams CJ, Krawczyk DC. Who am I? How do I look? Neural differences in self-identity in anorexia nervosa. Soc Cogn Affect Neurosci. 2014;9(1):12-21.

112. Murray RJ, Debbane M, Fox PT, Bzdok D, Eickhoff SB. Functional connectivity mapping of regions associated with self- and otherprocessing. Hum Brain Mapp. 2015;36(4):1304-1324.

113. Cabanis M, Pyka M, Mehl S, et al. The precuneus and the insula in self-attributional processes. Cogn Affect Behav Neurosci. 2013;13(2): $330-345$.

114. Goddard E, Hibbs R, Raenker S, et al. A multi-centre cohort study of short term outcomes of hospital treatment for anorexia nervosa in the UK. BMC Psychiatry. 2013;13:287.

115. Lock J, le Grange D. Family-based treatment of eating disorders. Int J Eat Disord. 2005;37(Supp1):S64-S67; discussion S87-S69.

116. Stiles-Shields C, Hoste RR, Doyle PM, Le Grange D. A review of family-based treatment for adolescents with eating disorders. Rev Recent Clin Trials. 2012;7(2):133-140.

117. Thompson-Brenner H, Shingleton RM, Sauer-Zavala S, Richards LK, Pratt EM. Multiple measures of rapid response as predictors of remission in cognitive behavior therapy for bulimia nervosa. Behav Res Ther. 2015;64:9-14.

118. Nook EC, Zaki J. Social norms shift behavioral and neural responses to foods. J Cogn Neurosci. 2015;27(7):1412-1426.

119. Lewis SP, Arbuthnott AE. Searching for thinspiration: the nature of internet searches for pro-eating disorder websites. Cyberpsychol Behav Soc Netw. 2012;15(4):200-204.

120. Teufel M, Hofer E, Junne F, Sauer H, Zipfel S, Giel KE. A comparative analysis of anorexia nervosa groups on Facebook. Eat Weight Disord. 2013;18(4):413-420.

121. Friederich HC, Wu M, Simon JJ, Herzog W. Neurocircuit function in eating disorders. Int J Eat Disord. 2013;46(5):425-432.

122. Downar J, Geraci J, Salomons TV, et al. Anhedonia and reward-circuit connectivity distinguish nonresponders from responders to dorsomedial prefrontal repetitive transcranial magnetic stimulation in major depression. Biol Psychiatry. 2014;76(3):176-185.

123. Downar J, Sankar A, Giacobbe P, Woodside B, Colton P. Unanticipated rapid remission of refractory bulimia nervosa, during high-dose repetitive transcranial magnetic stimulation of the dorsomedial prefrontal cortex: a case report. Front Psychiatry. 2012;3:30.

124. Shenhav A, Straccia MA, Cohen JD, Botvinick MM. Anterior cingulate engagement in a foraging context reflects choice difficulty, not foraging value. Nat Neurosci. 2014;17(9):1249-1254.

125. Bulik CM, Baucom DH, Kirby JS. Treating anorexia nervosa in the couple context. J Cogn Psychother. 2012;26(1):19-33.

126. Lock J. An update on evidence-based psychosocial treatments for eating disorders in children and adolescents. J Clin Child Adolesc Psychol. 2015:1-15.

127. Robinson P, Barrett B, Bateman A, et al. Study protocol for a randomized controlled trial of mentalization based therapy against specialist supportive clinical management in patients with both eating disorders and symptoms of borderline personality disorder. BMC Psychiatry. 2014;14:51.

128. Silverstone PH. Is chronic low self-esteem the cause of eating disorders? Med Hypotheses. 1992;39(4):311-315.
129. Button EJ, Sonuga-Barke EJ, Davies J, Thompson M. A prospective study of self-esteem in the prediction of eating problems in adolescent schoolgirls: questionnaire findings. Br J Clin Psychol. 1996; 35(pt 2):193-203.

130. Daley KA, Jimerson DC, Heatherton TF, Metzger ED, Wolfe BE. State self-esteem ratings in women with bulimia nervosa and bulimia nervosa in remission. Int J Eat Disord. 2008;41(2):159-163.

131. Handley AK, Egan SJ, Kane RT, Rees CS. A randomised controlled trial of group cognitive behavioural therapy for perfectionism. Behav Res Ther. 2015;68:37-47.

132. Halmi KA, Agras WS, Crow S, et al. Predictors of treatment acceptance and completion in anorexia nervosa: implications for future study designs. Arch Gen Psychiatry. 2005;62(7):776-781.

133. Mischner IH, van Schie HT, Wigboldus DH, van Baaren RB, Engels RC. Thinking big: the effect of sexually objectifying music videos on bodily self-perception in young women. Body Image. 2013;10(1):26-34.

134. Mischner IH, van Schie HT, Engels RC. Breaking the circle: challenging western sociocultural norms for appearance influences young women's attention to appearance-related media. Body Image. 2013;10(3):316-325.

135. Somerville LH, Kelley WM, Heatherton TF. Self-esteem modulates medial prefrontal cortical responses to evaluative social feedback Cereb Cortex. 2010;20(12):3005-3013.

136. Miyake Y, Okamoto Y, Onoda K, Kurosaki M, Shirao N, Yamawaki S. Brain activation during the perception of distorted body images in eating disorders. Psychiatry Res. 2010;181(3):183-192.

137. Miyake Y, Okamoto Y, Onoda K, Shirao N, Otagaki Y, Yamawaki S. Neural processing of negative word stimuli concerning body image in patients with eating disorders: an fMRI study. Neuroimage. 2010; 50(3):1333-1339.

138. Oberndorfer TA, Kaye WH, Simmons AN, Strigo IA, Matthews SC. Demand-specific alteration of medial prefrontal cortex response during an inhibition task in recovered anorexic women. Int J Eat Disord. 2011;44(1):1-8.

139. Brooks SJ, O’Daly OG, Uher R, Schioth HB, Treasure J, Campbell IC. Subliminal food images compromise superior working memory performance in women with restricting anorexia nervosa. Conscious Cogn. 2012;21(2):751-763.

140. Wierenga C, Bischoff-Grethe A, Melrose AJ, et al. Altered BOLD response during inhibitory and error processing in adolescents with anorexia nervosa. PLoS One. 2014;9(3):e92017.

141. Garrett AS, Lock J, Datta N, Beenhaker J, Kesler SR, Reiss AL. Predicting clinical outcome using brain activation associated with setshifting and central coherence skills in anorexia nervosa. J Psychiatr Res. 2014;57:26-33.

142. Young KD, Zotev V, Phillips R, et al. Real-time FMRI neurofeedback training of amygdala activity in patients with major depressive disorder. PLoS One. 2014;9(2):e88785.

143. Moll J, Weingartner JH, Bado P, et al. Voluntary enhancement of neural signatures of affiliative emotion using FMRI neurofeedback. PLoS One. 2014;9(5):e97343.
Neuroscience and Neuroeconomics

\section{Publish your work in this journal}

Neuroscience and Neuroeconomics is an international, peer-reviewed, open access journal focusing on the identification of brain structure and measurement of neural activity related to behavior, behavioral predictions, and decision making in health and disease. The manuscript

\section{Dovepress}

management system is completely online and includes a very quick and fair peer-review system. Visit http://www.dovepress.com/testimonials. php to read real quotes from published authors. 